\title{
Quantified and applied sea-bed dynamics of the Netherlands Continental Shelf and the Wadden Sea
}

\author{
Thaiënne A.G.P. van Dijk ${ }^{1 \mathrm{a}, 2}$, M.H.P. Kleuskens ${ }^{3}$, L.L. Dorst ${ }^{4}$, C. van der Tak ${ }^{5}$, P.J. Doornenbal ${ }^{1 \mathrm{a}}$, \\ A.J.F. van der Spek ${ }^{1 a, 6}$, R.M. Hoogendoorn ${ }^{1 a}$, D. Rodriguez Aguilera ${ }^{1 b}$, P.J. Menninga ${ }^{7}$ and R.P. \\ Noorlandt ${ }^{1 \mathrm{a}, 8}$ \\ ${ }^{1 a}$ Applied Geology and Geophysics, Deltares, P.O. Box 85467, 3508 AL, Utrecht, The Netherlands, thaienne.vandijk@deltares.nl \\ ${ }^{1 b}$ Soil and Groundwater Quality, Deltares, P.O. Box 85467, 3508 AL, Utrecht, The Netherlands \\ ${ }^{2}$ Water Engineering and Management, University of Twente, P.O. Box 217, 7500 AE, Enschede, The Netherlands \\ ${ }^{3}$ Alten PTS, 5651 CD Eindhoven, The Netherlands \\ ${ }^{4}$ Hydrographic Service, Royal Netherlands Navy, P.O. Box 90701, 2509 LS, The Hague, The Netherlands \\ ${ }^{5}$ MARIN, P.O. Box 28, 6700 AA Wageningen, The Netherlands \\ ${ }^{6}$ Netherlands Centre for Coastal Research (NCK), Delft University of Technology, Faculty of Civil Engineering and Geosciences, \\ P.O. Box 5048, 2600 GA, Delft, The Netherlands \\ ${ }^{7}$ Institute for Marine and Atmospheric research Utrecht (IMAU), Utrecht University, P.O. Box 80.005, 3508 TA, Utrecht, The \\ Netherlands \\ ${ }^{8}$ Department of Geotechnology, Delft University of Technology, P.O. Box 5048, 2600 GA, Delft, The Netherlands
}

\begin{abstract}
Sedimentary coasts and shallow-sea beds may be dynamic. The large-scaled spatial variation in these dynamics and the smaller-scaled behaviour of individual marine bedforms are largely unknown. Sea-bed dynamics are relevant for the safety of shipping, and therefore for monitoring strategies, and for offshore engineering projects and archaeological investigations. To date, sea-bed dynamic studies in the North Sea that are based on high-resolution echo soundings are mostly local. Recently, sufficient time series of modern, digital echo sounder surveys have become available to allow for a Netherlands Continental Shelf-wide quantification of vertical dynamic trends as well as for the detailed analysis of the morphodynamics of marine bedforms. Results show that (i) tidal channels, estuaries and longshore bars are particularly dynamic, (ii) the shelf offshore is less dynamic in general, and (iii) the most dynamic zones offshore are the zones where marine bedforms occur. The occurrence of superimposed sand banks, long bed waves, sand waves and megaripples is limited to the sandy shelf and sand wave migration rates vary spatially between 0 to $20 \mathrm{~m} /$ year. This spatial knowledge of morphodynamics is used in combination with environmental conditions and sea traffic to validate and to optimise re-survey policies.
\end{abstract}

\section{INTRODUCTION}

Sandy continental shelves and sedimentary coasts may be dynamic. Most sandy sea beds of shallow seas are characterized by marine bedforms of different spatial scales, such as sand banks, long bed waves, sand waves and megaripples. Each of these bedforms has its own dynamic time scale. These dynamics are relevant for navigation safety, especially in seas with critical depths for shipping, such as the southern North Sea. In order to keep nautical maps up-to-date, dynamic sea beds need to be resurveyed in an appropriate frequency. Guidelines for horizontal and vertical accuracy of the data are provided by the International Hydrographic Organization [IHO, 2008], but no guidelines for the validation and optimization of re-survey policies exist. Other applications are offshore engineering projects, such as wind farms, and archaeological investigations.

Previous empirical studies of seabed morphodynamics focused on the analysis of marine bedforms of small sites with specific local conditions [e.g. Duffy and Hughes-Clarke, 2005; Knaapen, 2005; Van Dijk and Kleinhans, 2005; Winter and Ernstsen, 2007; Buijsman and Ridderinkhof, 2008; Van Dijk et al., 2008; Dorst et al., 2009; Dorst et al., 2011]. Although recently performed for the
German coastal zone [Winter, 2011], a large-scaled study of the morphodynamics of the Netherlands Continental Shelf (NCS) does not exist. Such a study provides an overview of the spatial variation in seabed dynamics that increases our insight and understanding of the processes of bed evolution.

Only recently, the coverage of multiple datasets (time series) of digital bathymetric data, which are required for the study of seabed morphodynamics, has become sufficient for the NCS to perform this study. In addition, the horizontal precision of these modern data is adequate for the detailed and quantitative analyses of bed changes and bedform mobility.

The aim of this paper is to present the vertical sea-bed dynamics of the Netherlands Continental Shelf and the Wadden Sea, based on a quantitative analysis on a $25 \times 25 \mathrm{~m}$ resolution. Detailed analyses of selected locations serve to describe the local morphology and dynamics of individual bedforms.

\section{DATA AND METHODS}

\section{Bathymetric data}

All data that are contained in the digital Bathymetric Archive System (BAS) of the Hydrographic Service of the Royal 


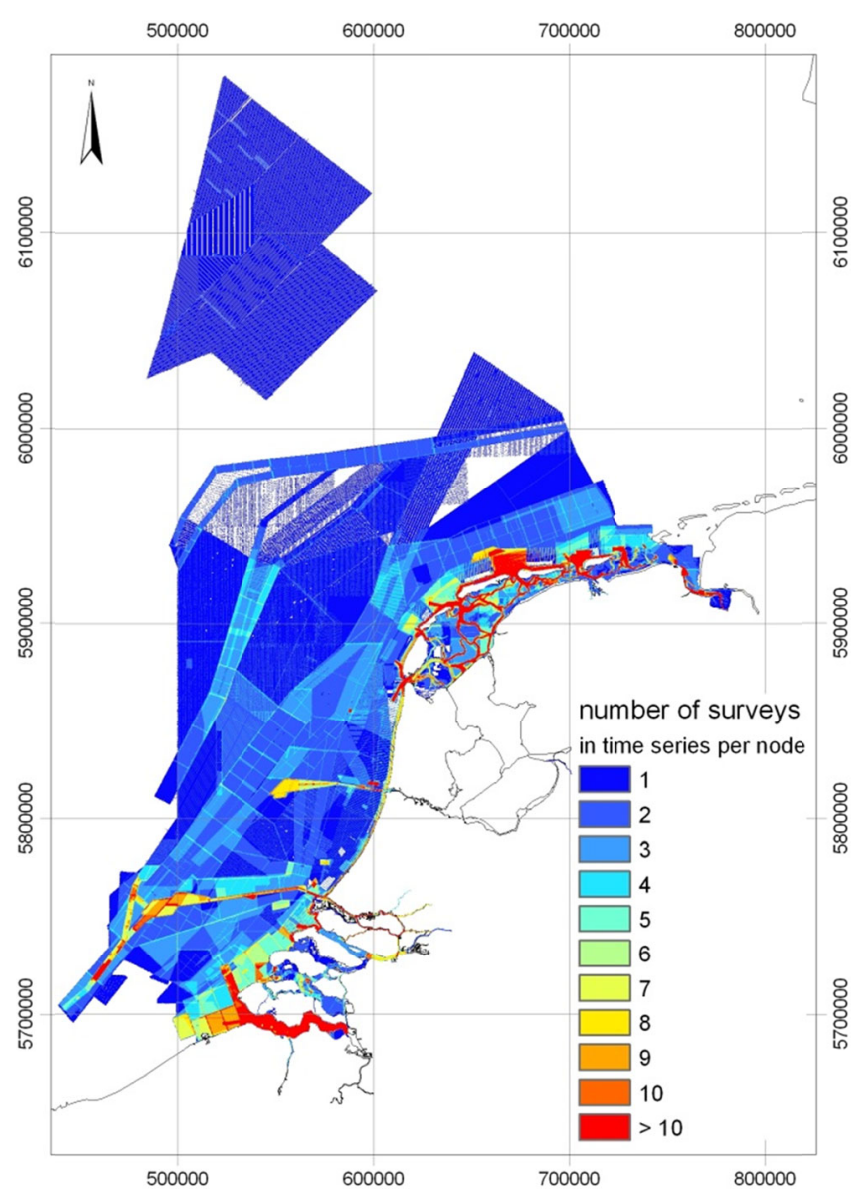

Figure 1. Number of digital datasets included in a time series per grid node (UTM31 WGS84 co-ordinates). In most areas where only one dataset was available, fair sheets were digitized to create a time series of 2 datasets.

Netherlands Navy below the $10 \mathrm{~m}$ isobath [Righolt et al., 2010] were used in this study. This database includes data acquired by Rijkswaterstaat for the shallower coastal zone. Digital data in BAS comprise both single-beam echo soundings (SBES) and multibeam echo soundings (MBES), that were collected according to the Order 1 standards for hydrographic surveys of the International Hydrographic Organization [IHO, 2008].

The overlap of surveys creates time series of various spatial extents and different periods. Most time series comprise two or three datasets; at few locations on the NCS, time series of more than 5 datasets exist (Figure 1). In locations where time series did not exist, historical echo soundings were digitized from plotted or hand-written fair sheets in order to create a bathymetric time series. The data density and precision (horizontal positioning and echo sounding beams) differ per method and in time. The digital datasets used in this study were acquired between the late 1980s and June 2010. The fair sheets date from before that. Data density used in this study is at most 1 observation per $3 \times 5 \mathrm{~m}$.

Digital Elevation Models (DEMs) were created from these bathymetric data by interpolating to a $25 \times 25 \mathrm{~m}$ grid, using the Inverse Distance Weighting algorithm with a search radius of 100 $\mathrm{m}$. This $25 \mathrm{~m}$ resolution was chosen to still represent sand waves (hundreds of meters in length) well and to minimize the introduction of interpolation artefacts of single beam echo soundings in track lines. Megaripples cannot be characterized at this resolution, but are often not captured by single beam data in the first place.

\section{Vertical nodal dynamic analysis}

Because we deal with numerous overlaps of various extents, different numbers of surveys and different periods, it is insufficient to use average values of bed elevation change in meters. For the quantitative analysis of vertical dynamic trends $(\mathrm{m} / \mathrm{yr})$ for each grid node, we developed a fully automated linear regression of all bed elevations in the stacked time series per node (Figure 2). Based on visual inspection of the nodal bed elevations in time, linear regression is justified within in the periods that are covered by the time series. We used an averaged date of collection per survey, because the periods of acquisition are relatively short and never were a problem for the precision of the calculations. Because the correction for tides and ship movements provided differences between surveys that are larger than the (natural) vertical dynamics, we corrected for this discrepancy by subtracting the averaged vertical dynamics for each specific stacked combination of surveys from the vertical dynamics at each node (Figure 3).

\section{Geometry and mobility of individual bedforms}

For the detailed morphological and dynamic analyses of individual sand waves and long bed waves, the bathymetric signal is separated into bedform types of different spatial scales by truncating a Fourier approximation at certain frequencies [for details, see Van Dijk et al., 2008]. This way, the more dynamic

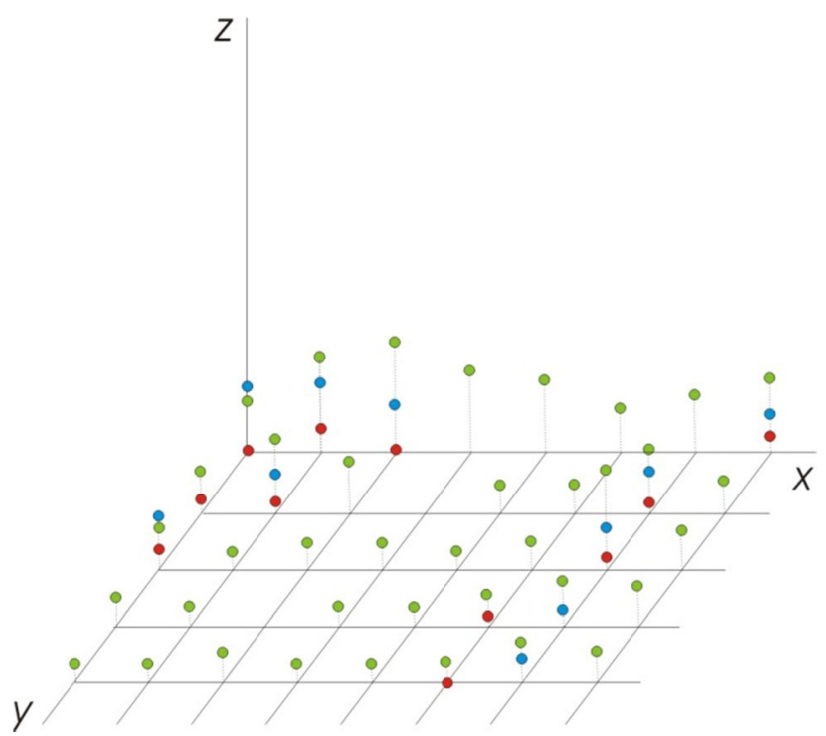

Figure 2. Illustration of different bathymetric datasets in a time series, displaying two sets of single-bean echo soundings (red and blue) distributed in track lines that do not exactly overlap and one set of multibeam echo soundings (green). The stacked time series for node $(0,0)$ comprises three data points (red, green, blue). 
(a)

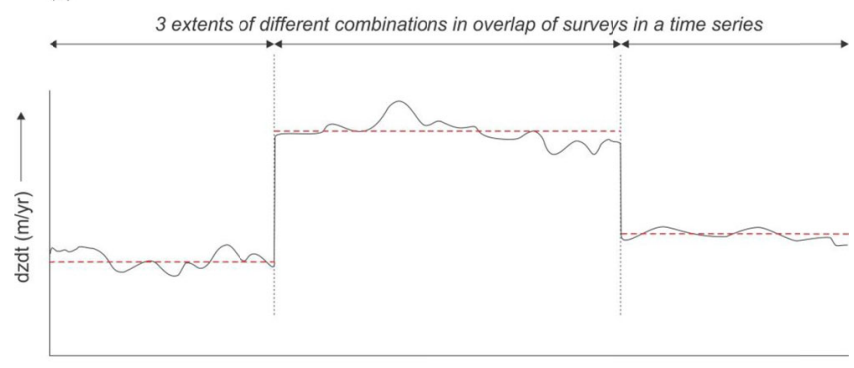

distance along cross section $\longrightarrow$

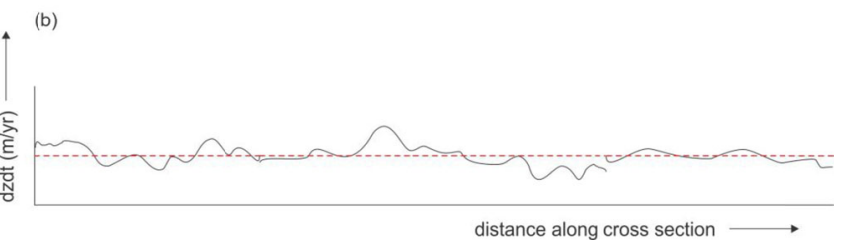

Figure 3. Applied correction in calculating the vertical nodal dynamics of the NCS. (a) The calculated dynamics (black solid line) are corrected by subtracting the average dynamics for each combination of survey overlap (red dashed lines) (b) Resulting morphodynamics in which the patchwork is removed and the natural seabed dynamics are revealed.

megaripples (contained in multibeam data), which may obscure the sand wave or long bed wave dynamics, are removed. From the smoothed bedform signal, locations of crest, trough and inflection points are then determined in a semi-automated way, from which the geometry and dynamics of individual bedforms is calculated.

\section{RESULTS}

\section{Vertical dynamics trends}

The quantified vertical nodal dynamic trends for the Netherlands Continental Shelf (Figure 4) provide an overview of regions of contrasting dynamics on the NCS. In this map, vertical dynamic trends are simplified into classes of absolute values in order to amplify the dynamic contrasts. Thus, this map does not display the full range of dynamic trends, which apart from extremes may range between few decimeters per year degradation or aggradation.

In general, the coastal zone is more dynamic than the continental shelf. Three zones of contrasting (natural) dynamics may be distinguished. First, the highly dynamic coastal zone includes estuaries, tidal inlets with ebb-tidal deltas, tidal channels in the Wadden sea and near-shore Zeeland, and breaker bars. Dynamic trends in these environments typically range between absolute values of 0.1 and $0.35 \mathrm{~m} / \mathrm{yr}$ with extremes up to $1.5 \mathrm{~m} / \mathrm{yr}$.

Second, areas of moderate dynamics occur offshore on mostly sandy parts of the NCS, where rhythmic bedforms are present. Here, values typically range between -0.1 to $0.1 \mathrm{~m} / \mathrm{yr}$ with extremes of an absolute $0.3 \mathrm{~m} / \mathrm{yr}$ in the sand wave fields. The appearance of bedform patterns in the vertical dynamics map indicates that the measure of vertical dynamics is controlled by the migration and/or growth of individual bedforms. Clear fields of relatively high dynamics are the sand wave field west of Texel, a long bed wave field north of Texel and Vlieland, and the entire sand wave field in the Southern Bight including tidal ridges and long bed waves. The tidal ridges $75 \mathrm{~km}$ offshore Texel, where sand waves seem to be absent, also display large vertical dynamics, although these results may in part be due to the lowresolution data of digitized fair sheets.

Third, offshore areas of very low sea-bed dynamics (around 0 $\mathrm{m} / \mathrm{yr}$; light blue) occur mostly in parts of the NCS where rhythmic bedforms are absent. Although the dynamics map is scarcely filled in these zones, the largest areas of low dynamics occur in the deeper parts of the NCS, farther offshore. The low-dynamic area north of de Wadden islands is unexpectedly stable in the sense that the shore-face connected ridges that occur here could have been susceptible to migration or growth/decay. In addition, areas of low seabed dynamics appear in a zone between the sand wave field west of Texel and the offshore sand banks, and in small patches along the coast offshore Den Haag, offshore Voorne and the Vlakte van de Raan (ebb-tidal delta of the Western Scheldt).

Other small parts of high vertical dynamics in Figure 4 are anthropogenic areas, such as sand extraction sites, and due to artefacts caused by the data in the time series. The latter are most prominent in the shipping lane in the centre of the map (Deep Water Route East) and in the zones of low dynamics north of the Wadden islands. The effect of data precision is also recognized in the contrasts of dynamics for the separate survey overlaps.

\section{Bedform size and mobility}

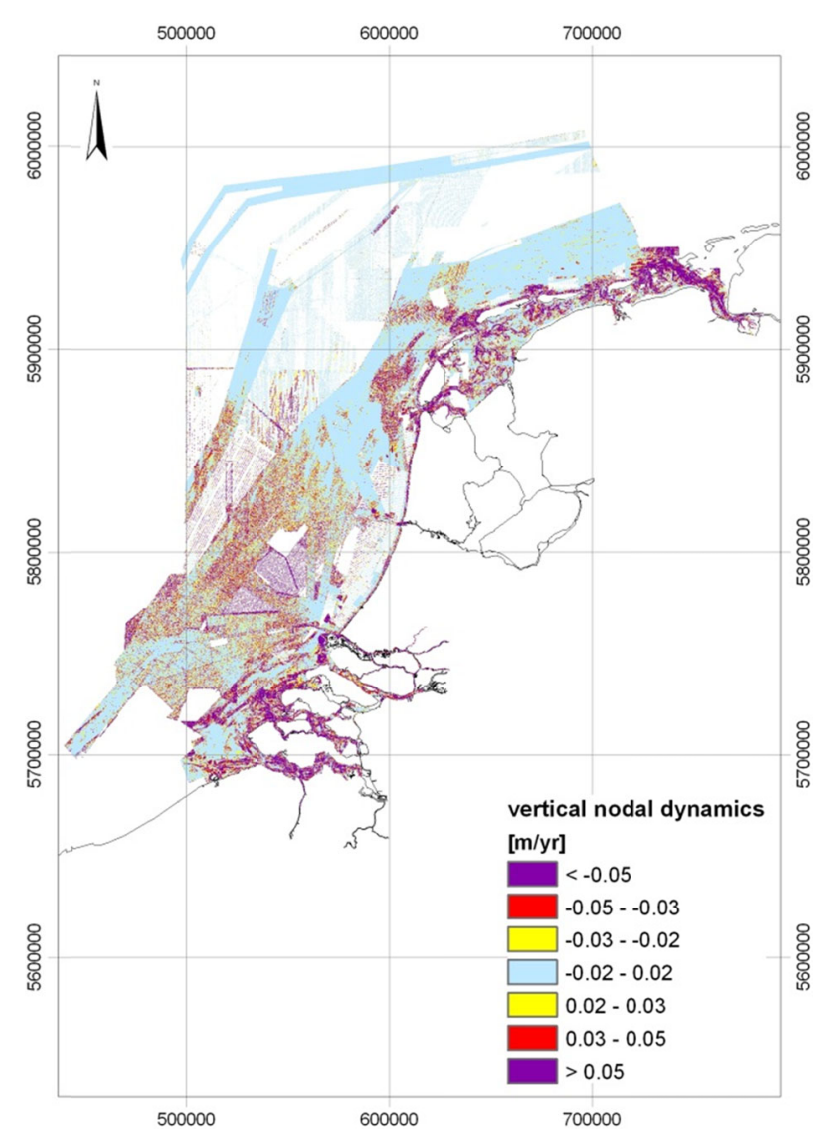

Figure 4. Vertical nodal dynamic trends of the Netherlands Continental Shelf (absolute values) show that the coastal zone is significantly more dynamic than the shelf, and that bed form fields offshore are the most dynamic zones on the shelf. Choice of classes is to amplify the morphodynamic contrasts; values range between -0.35 and $0.35 \mathrm{~m} / \mathrm{yr}$. 


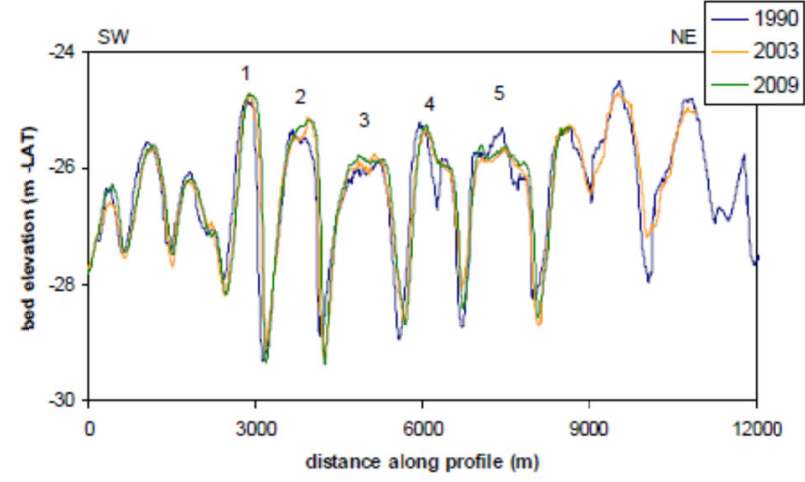

Figure 5. Profiles (SE to NW) of long bed waves north of Texel and Vlieland from the 1990, 2003 and 2009 datasets.

Detailed analyses of individual bedforms provide more information on the geometry, mobility and morphodynamics of bedforms. Three areas that are characterized by three different types of bedforms are here described.

Firstly, the sand wave field west of Texel comprises sand waves with an average wavelength of $345 \mathrm{~m}$ and an average wave height of $1.4 \mathrm{~m}$. With an average sand wave migration rate of 16 to 19 $\mathrm{m} / \mathrm{yr}$ to the northeast, this area is exceptionally dynamic compared to other sand wave fields on the NCS, where migration rates are mostly less than 5 m/yr [Van Dijk et al., 2008; Dorst et al., 2011; Van Dijk et al., 2011].

Secondly, five long bed waves in the dynamic field north of Texel and Vlieland were analyzed. Long bed waves were first identified by Knaapen et al. [2001], but migration rates were never reported. The long bed waves north of Texel have an average wavelength of $1125 \mathrm{~m}$ and an average wave height of 3.4 $\mathrm{m}$. Net migration rates, based on 3 surveys between 1990 and 2009 (Figure 5), range from 10.5 to $18.4 \mathrm{~m} / \mathrm{yr}$, with an average of $12.4 \mathrm{~m} / \mathrm{yr}$ to the northeast.

Thirdly, the shoreface-connected ridges north of Wadden islands were analyzed based on profiles of two datasets only (Figure 6). The average wavelength of the ridges is $4614 \mathrm{~m}$ and the average height is $4.3 \mathrm{~m}$. Present-day knowledge on migration rates and vertical morphodynamics of shoreface-connected ridges on the NCS is limited. Changes in dimensions are negligible and the average migration rate is $1.0 \mathrm{~m} / \mathrm{yr}$ to the southwest.

\section{DISCUSSION}

A large-scaled study of vertical bed level changes of a wide coastal zone of the German Continental Shelf was recently performed by Winter [2011]. His calculations are based on a large number of annual datasets near the coast (up to 30 for two estuaries) and a small number of datasets (less than 5) farther offshore. Although his results are presented as bed elevation range (difference between the maximum and minimum bed levels) per node (in meters) and are thus not directly comparable to our dynamic trends (in $\mathrm{m} / \mathrm{yr}$ ), the overall pattern of dynamics is in good agreement with our findings of the NCS. Winter also describes highly dynamic estuaries and tidal inlets between the Wadden islands and areas of low dynamics offshore, which connects very well to the vertical dynamics map of the Dutch Wadden presented in this paper.
A regional bed dynamics study for the Wadden Sea, using a time series from 1926 to 2006, was carried out by Vonhögen et al. [2010]. They expressed dynamics in terms of the net deposition $(\mathrm{cm})$, thus the difference between the latest and the lowest bed levels in the time series. Although these values are also not directly comparable to our dynamic trends in $\mathrm{m} / \mathrm{yr}$, the pattern of highly-dynamic tidal channels corresponds well and therewith corroborates our findings.

For the shoreface-connected ridges, in comparison, shorefaceconnected ridges at the north coast of Spiekeroog, one of the German Wadden islands, also migrate landwards, but are much more dynamic [Antia, 1996]. The maximum migration rate of $100-200 \mathrm{~m} / \mathrm{yr}$ is a factor $100-200$ higher than the migration we find, and 4 to 40 times higher than rates reported from ridges in North-America, which range from mearly stable to $6 \mathrm{~m} / \mathrm{yr}$ [Antia, 1996, and references therein]. Although the environment of the

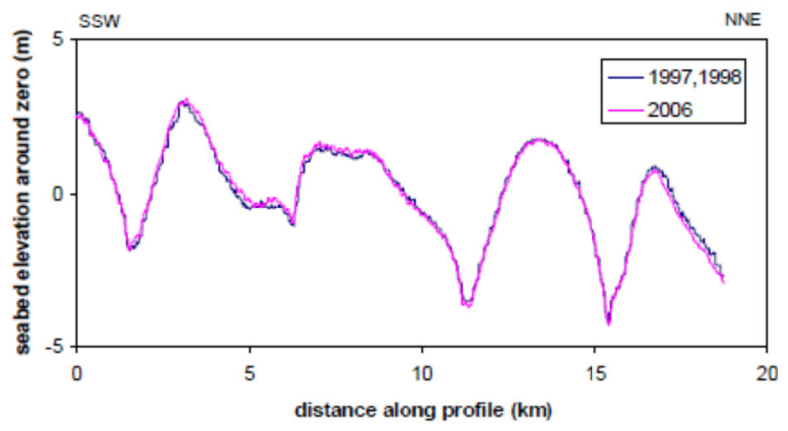

Figure 6. Profiles (SSW to NNE) of the shoreface-connected ridges north of the Wadden islands indicate that these bedforms have neither grown nor migrated in almost a decade.

banks at Spiekeroog seems similar to the shoreface-connected ridges at Ameland and Schiermonnikoog, the former banks are shorter and lower.

As the controlling parameters of the spatial variation in sea-bed dynamics, we hypothesise that:

- grain size affects the presence of sand waves and also may be a proxy for spatial variation in bedform migration rates, since an overlay of median grain sizes and bed morphology \& dynamics correspond very well;

- current velocity seems the dominant factor for dimensions of sand waves [for wave length, see also Van Santen et al., 2011] and sediment transport potential seems related to the migration rate of sand waves and long bed waves, when we compare modeled sediment transport rates of the North Sea [Van der Molen and De Swart, 2001] and an overview study of Bearman [1999] to our sand wave migration rates.

The vertical dynamic trends are sensitive to data quality issues, such as data density and precision. Low-resolution data, especially the older datasets, may underestimate the bedform heights and also affect the location of crests and troughs. In general, a lower data resolution of one dataset results in a higher vertical dynamics when comparing to another dataset. 


\section{APPLICATIONS}

Without knowledge of the sea-bed dynamics, re-survey policies of continental shelves and rivers cannot be validated. The above analysis was used to validate and to optimize the survey-policy of the Netherlands Hydrographic Office. Hereto, we combined the morphodynamics and the predicted grounding dangers for shipping, based on shipping intensity, predicted water depth and the probability of unknown objects at the bed. An ongoing study on the river- and sea-bed dynamics for Rijkswaterstaat includes the investigation of cause and effects, including the interaction between dredging activities and sand waves.

Other applications are advice on sea-bed stability for regional planning and offshore engineering projects, such as the allocation, construction and maintenance of offshore wind farms. Bedform mobility may affect the depth of wind piles into the sea bed by maximally the bedform height, which may be up to several meters.

Finally, knowledge on the morphodynamics of tidal channels and sand banks is crucial in refining the 3D geological model of the subsurface, the evolution of the marine palaeolandscape and the prediction of archaeological remnants, such as shipwrecks and subrecent archaeology (e.g. WOII-remnants). Sea-bed dynamics also play a role in the burial and exposure of shipwrecks, so establishing the affected depths and time-scales of these dynamics provide information on the preservation potential of these archaeological items.

\section{CONCLUSIONS}

Vertical nodal dynamic trends of the Netherlands Continental Shelf typically vary between -0.35 and $0.35 \mathrm{~m} / \mathrm{yr}$. The coastal zone is significantly more dynamic than the offshore zone. Especially estuaries, tidal inlets, tidal channels and breaker bars are dynamic (abs. values of $0.1-0.35 \mathrm{~m} / \mathrm{yr}$, with extremes up to $1.5 \mathrm{~m} / \mathrm{yr}$ ). Offshore the most dynamic parts are the fields of mobile marine bedforms, such as sand waves and long bed waves, where vertical bed levels are caused by bedform migration and/or growth (levels between -0.1 and $0.1 \mathrm{~m} / \mathrm{s}$ with extremes up to an abs. $0.35 \mathrm{~m} / \mathrm{yr}$ ). Deeper parts and north of the Wadden islands, vertical dynamics are very low $(\sim 0 \mathrm{~m} / \mathrm{yr})$.

Vertical trends in sea-bed dynamics are crucial in the re-survey policies of hydrographic surveyors. By combining the (predicted) sea-bed dynamics with predicted grounding dangers for sea traffic, monitoring policies can be optimized so that measuring efforts are low while safety is still the highest. To offshore engineers, managers and marine archaeologists, morphodynamics support the decision-making on regional planning, marine protected areas and archaeological values and the potential risks to offshore structures and maintenance.

\section{ACKNOWLEDGEMENT}

All data were provided by the Hydrographic Office, Royal Netherlands Navy, and Rijkswaterstaat, Ministry of Infra Structure and the Environment. Most of this work was carried out within a research project financed by the Ministry of Defense. Within this project, the Maritime Research Institute of the Netherlands (MARIN) quantified the grounding dangers for shipping.

\section{REFERENCES}

Antia, E.E. (1996), Rates and patterns of migration of shorefaceconnected ridges along the sourthern North Sea coast, Journal of Coastal Research, 12, 38-46.

Bearman, G. (Ed.) (1999), Waves, tides and shallow-water processes, second ed., 227 pp., Butterworth-Heinemann, Oxford.

Buijsman, M.C. and Ridderinkhof, H. (2008), Long-term evolution of sand waves in the Marsdiep inlet, II: relation to hydrodynamics, Continental Shelf Research, 28, 1202-1215.

Dorst, L.L., Roos, P.C. and Hulscher, S.J.M.H. (2011), Spatial differences in sand wave dynamics between the Amsterdam and the Rotterdam region in the Southern North Sea, Continental Shelf Research, 31, 1096-1105.

Dorst, L.L., Roos, P.C., Hulscher, S.J.M.H. and Lindenbergh, R.C. (2009), The estimation of sea floor dynamics from bathymetric surveys of a sand wave area, Journal of Applied Geodesy, 3, 97120.

Duffy, G.P. and Hughes-Clarke, J.E. (2005), Application of spatial cross correlation to detection of migration of submarine sand dunes, Journal of Geophysical Research, 110.

IHO (2008), IHO Standards for Hydrographic Surveys, edited, International Hydrographic Bureau, Monaco.

Knaapen, M.A.F. (2005), Sandwave migration predictor based on shape information Journal of Geophysical Research, 110, 9.

Knaapen, M.A.F., Hulscher, S.J.M.H., de Vriend, H.J. and Stolk, A. (2001), A new type of sea bed waves, Geophysical Research Letters, 28, 1323-1326.

Righolt, R.H., Schaap, J., Dorst, L.L. and Vos, E.M. (2010), Needle in a haystack, in Management of massive point cloud data: wet and dry, edited by P.J.M. Van Oosterom, M.G. Vosselman, T.A.G.P. Van Dijk and M. Uitentuis, p. 104, Nederlandse Commissie voor Geodesie, Delft.

Van der Molen, J. and De Swart, H.E. (2001), Holocene wave conditions and wave-induced sand transport in the southern North Sea, Continental Shelf Research, 21, 1723-1749.

Van Dijk, T.A.G.P. and Kleinhans, M.G. (2005), Processes controlling the dynamics of compound sand waves in the North Sea, Netherlands, Journal of Geophysical Research, 110.

Van Dijk, T.A.G.P., Lindenbergh, R.C. and Egberts, P.J.P. (2008), Separating bathymetric data representing multi-scale rhythmic bedforms: a geostatistical and spectral method compared, Journal of Geophysical Research, 113.

Van Dijk, T.A.G.P., Van der Tak, C., De Boer, W.P., Kleuskens, M.H.P., Doornenbal, P.J., Noorlandt, R.P. and Marges, V.C. (2011), The scientific validation of the hydrographic survey policy of the Netherlands Hydrographic Office, Royal Netherlands Navy, 165 pp, Deltares.

Van Santen, R.B., De Swart, H.E. and Van Dijk, T.A.G.P. (2011), Sensitivity of tidal sand wavelength to environmental parameters: A combined data analysis and modelling approach, Continental Shelf Research, 31, 966-978.

Vonhögen, L.M., Van Heteren, S., Marges, V.C., Wiersma, A.P. and De Kleine, M.P.E. (2010), Comparison between the internal dynamics of the Dutch Wadden Sea and the volumes involved by subsidence areas, paper presented at NCK days 2010, WestKapelle, Netherlands.

Winter, C. (2011), Macro scale morphodynamics of the German North Sea coast, Journal of Coastal Research, SI 64, 706 - 710.

Winter, C. and Ernstsen, V.B. (2007), Spectral analysis of compound dunes, paper presented at 5th IAHR Symposium on River, Coastal and Estuarine Morphodynamics (RCEM 2007), Taylor \& Francis, University of Twente, Enschede, The Netherlands 